\title{
Tramadol/Diclofenac Fixed-Dose Combination: A Review of Its Use in Severe Acute Pain
}

Dilip D. Shah · Zubair H. Sorathia

Received: October 4, 2019 / Published online: February 15, 2020

(C) The Author(s) 2020

\begin{abstract}
Pain is a health issue affecting all populations, regardless of age, gender, economic status, race, or geography. Acute pain is the most common type of pain, with a complex aetiology. Inadequately managed acute pain adversely affects quality of life and imposes significant economic burden. The majority of the available pain-relieving drugs have monomodal mechanisms of analgesia, which necessitates combining drugs with non-redundant mechanisms of action in order to provide adequate pain relief and reduce the side effects from higher doses of individual drugs. In this regard, combining an oral opioid (such as codeine or tramadol) and a non-opioid (such as paracetamol or non-steroidal anti-inflammatory drug) offers a plausible option.
\end{abstract}

Enhanced Digital Features To view enhanced digital features for this article go to https://doi.org/10.6084/ m9.figshare.11636919.

D. D. Shah $(\square)$

Jewel Nursing Home, Plot No 89, Ns Road No 1, Andheri West, Mumbai 400058, India

e-mail: journalsubmission911@gmail.com

Z. H. Sorathia

Medicare Hospital, Marol Naka Metro Station,

Andheri East, Mumbai 400059, India
Tramadol/diclofenac fixed-dose combination (FDC) is one such analgesic combination which has demonstrated promising clinical activity via its multimodal mechanisms of action. This review seeks to provide an up-to-date narrative on the current scientific literature regarding the pharmacological properties, clinical efficacy, and tolerability of tramadol/diclofenac FDC in the treatment of acute severe pain. A comprehensive, qualitative review of the literature was conducted using a structured search strategy in Medline/PubMed and additional Internet-based sources to identify relevant studies. Based on the available scientific literature, evidence of the efficacy and safety of tramadol/diclofenac FDC for treatment of patients with acute severe pain, including musculoskeletal pain, postoperative pain, and acute flare-up of osteoarthritis or rheumatoid arthritis, appears to be substantial. Although additional comparative studies would be required to definitively position tramadol/diclofenac FDC with respect to other analgesic combinations, the available data suggest that tramadol/diclofenac FDC is a valuable treatment option for patients with acute severe pain.

Keywords: Acute pain; Analgesia; Codeine; Diclofenac; Musculoskeletal pain; Pain management; Tramadol 


\section{Key Summary Points}

Why carry out this study?

Acute pain is the most common type of pain, with a complex aetiology which may adversely affect quality of life and impose an economic burden.

The majority of the available painrelieving drugs have monomodal mechanisms of analgesia. However, tramadol/diclofenac fixed-dose combination (FDC) is an analgesic combination which has demonstrated promising clinical activity via its multimodal mechanisms of action.

This comprehensive, qualitative review seeks to provide an up-to-date narrative on the current scientific literature regarding the pharmacological properties, clinical efficacy, and tolerability of tramadol/diclofenac FDC in the treatment of acute severe pain.

\section{What was learned from the study?}

Based on the available scientific literature, there appears to be substantial evidence of the efficacy and safety of tramadol/ diclofenac FDC for treatment of patients with acute severe pain, including musculoskeletal pain, postoperative pain, and acute flare-up of osteoarthritis or rheumatoid arthritis.

Although additional comparative studies would be required to definitively position tramadol/diclofenac FDC with respect to other analgesic combinations, available data suggest that tramadol/diclofenac FDC is a valuable treatment option for patients with acute severe pain.

\section{INTRODUCTION}

The International Association for the Study of Pain defines pain as "an unpleasant sensory and emotional experience associated with actual or potential tissue damage or described in terms of such damage" [1]. Pain is a public health issue worldwide and remains the most common cause for physician consultation and hospital admission [2]. Pain affects all populations, regardless of age, gender, economic status, race, or geography [2]. Acute pain is the most common type of pain, and can occur due to injury, acute illness, surgery, or arthritis, making its aetiology a complex and transdisciplinary affair $[2,3]$. The global prevalence of postoperative pain varies from 14 to $70 \%$, and the scenario is even more serious in India, where $>80 \%$ of patients experience postoperative pain [4-8]. Pain due to musculoskeletal disorders is another common form of acute pain, and occupationspecific prevalence is reported to be $\sim 90 \%$ in India [9]. Acute flare-ups of rheumatoid arthritis and osteoarthritis are significant contributors to the burden of acute pain in India. Inadequately managed acute pain adversely affects quality of life, physical function, and functional recovery $[10,11]$. Moreover, inadequately managed pain leads to significant economic burden in terms of healthcare utilisation and labour force participation $[12,13]$.

\section{Current Challenges in, and the Available Options for, the Effective Management of Acute Pain}

Despite recent advances in the understanding of the cellular mechanisms underlying pain initiation, including the discovery of novel molecular targets, the management of acute pain remains suboptimal in the majority of patients [14-18]. Consequently, there is an unmet need to identify and address the barriers to appropriate management of acute pain [18]. This could be addressed in part with increased appreciation of the complex interplay between the peripheral and central nervous systems in pain transmission, facilitation, and inhibition [18].

The current armamentarium for pain management comprises multiple options, the majority based on monomodal mechanisms of analgesia [19, 20]. However, acute pain is 
multidimensional in nature, involving sensory, affective, cognitive, and behavioural aspects. Therefore, achieving adequate pain control with a single drug may not be beneficial $[19,20]$. Moreover, most analgesics exhibit a ceiling of efficacy and have significant safety concerns [21]. An optimal approach to multimodal pain management might be to combine drugs with non-redundant mechanisms of action that would provide adequate pain relief and also reduce side effects. Emerging evidence shows additive or synergistic actions of multimodal analgesia in various combinations of analgesic agents [22]. Combining analgesics has several advantages, such as a broader spectrum of action, improved efficacy and compliance, and a better efficacy/safety ratio [23]. A line of evidence shows that the combination of opioids and non-steroidal anti-inflammatory drugs (NSAIDs) improves efficacy and reduces the dose of individual drugs when compared with monotherapy [22, 24-26]. Given the clinical significance of these benefits and the current global concerns regarding the opioid epidemic, the American Pain Society (APS), World Health Organization (WHO), and American College of Rheumatology (ACR) now recommend analgesic combinations.

\section{Fixed-Dose Analgesic Combinations}

Decreased pill burden, greater ease of administration, and the need for lower dosages of individual drug components are key benefits offered by fixed-dose combination (FDC) analgesics. Combining oral opioids (such as codeine or tramadol) and non-opioids (such as paracetamol or NSAIDs) offers a more suitable option [27]. Among the currently available FDCs, paracetamol is the most commonly used nonopioid agent. In addition to the known hepatotoxic potential of paracetamol, its cardiovascular and gastrointestinal (GI) risk has been a recent cause for concern [28, 29]. Paracetamol also lacks the anti-inflammatory effect that is observed predominantly with NSAIDs [30]. Moreover, NSAIDS relieve pain more effectively than paracetamol or a paracetamol/codeine combination [31-33]. Combining NSAIDS with opioids, therefore, seems to be a preferable alternative. Due to the opioid-sparing action of NSAIDs, the combination of these two drugs significantly reduces opioid dose and mitigates the incidence of adverse events (AEs) such as nausea, vomiting, and respiratory depression. For an effective analgesic combination, the selection of the right NSAID and opioid agent at optimal doses is essential.

A combination of sustained-release diclofenac and immediate-release tramadol has recently been developed and widely used in clinical practice. This FDC provides multimodal analgesia at lower and better-tolerated doses than monotherapy with either drug [34, 35]. The selected doses are diclofenac $75 \mathrm{mg}$ and tramadol $50 \mathrm{mg}$. This FDC is available under the brand names DURAPAIN ${ }^{\circledR}$, RESYNC $^{\circledR}$, DIBOL $^{\circledR}$, and DIBOLS ${ }^{\circledR}$ in India. This review outlines the pharmacological properties, clinical efficacy, and tolerability of this FDC combination in adults with acute severe pain.

\section{METHODS}

\section{Source}

Medical literature published since 1986 on tramadol and/or diclofenac was identified using Medline/PubMed. Additional literature was identified from the reference lists of published articles. Other bibliographic information was also requested from the company manufacturing the drugs.

\section{Search Strategy}

Search terms used for PubMed were 'diclofenac plus tramadol' or 'tramadol and diclofenac combination' or 'tramadol' or 'diclofenac' or 'diclofenac plus tramadol bilayer tablet' or 'diclofenac/tramadol' or 'tramadol/diclofenac'. Searches were last updated on 6 December 2018.

\section{Selection}

Studies were selected based on the methods in which patients received tramadol/diclofenac. 


\section{Compliance with Ethics Guidelines}

This article is based on previously conducted studies and does not contain any studies with human participants or animals performed by any of the authors.

\section{PHARMACODYNAMIC PROPERTIES}

The pharmacodynamic properties of tramadol and diclofenac have been reviewed extensively elsewhere [36-45]. The key pharmacodynamic properties of both of these analgesic agents are described below.

\section{Tramadol}

Tramadol is an atypical opioid with a dual mode of action: it acts as a $\mu$-opioid receptor agonist and an inhibitor of monoamine neurotransmitter re-uptake, which together causes a reduction in afferent pain signalling and amplification of efferent inhibitory signalling [36-39, 46]. Unlike other opioids, tramadol acts primarily on the descending-inhibitory pathway of the central nervous system and inhibits the transmission and perception of pain $[36,38]$. The synergistic activity associated with the analgesic and anti-nociceptive effects of tramadol is due to the racemic nature of this molecule [37, 38]. Amongst two enantiomers, serotonin re-uptake inhibitor is $(+)$ tramadol, which has a higher affinity for $\mu$-opioid receptors, while (-) tramadol is a potent inhibitor of norepinephrine, and triggers auto-receptor activation [37, 38, 47]. Besides analgesia, other pharmacological actions of tramadol are similar to opioids, namely constipation, dizziness, sweating, nausea, somnolence, and pruritus. Unlike other opioid agents, treatment with tramadol is not associated with respiratory and cardiac depression. Further, drug dependence potential is low in patients who are treated with tramadol [37, 38]. Unlike morphine, tramadol does not cause histamine release $[39,48]$. Tramadol is metabolised via cytochrome $\mathrm{P} 450$ enzyme sparteine-oxygenase (CYP2D6), to $O$ desmethyltramadol (M1) in the liver [38, 48].
M1 has an approximately 200-fold higher affinity for $\mu$-receptor, which produces potent analgesic effects compared with $( \pm)$ tramadol $[38,40]$.

\section{Diclofenac}

Diclofenac is an NSAID exhibiting analgesic, anti-inflammatory, and antipyretic activity. Its mode of action is not well characterised. Although diclofenac is classified as a nonspecific COX inhibitor, it is a specific COX-2 isoform inhibitor which effectively inhibits prostaglandin-E2 and thromboxane-A2 synthesis and possesses pro-nociceptive action at peripheral and spinal sites $[49,50]$. Additionally, diclofenac acts as an eicosanoid oxidoreductase inhibitor and inhibits eicosanoids and lipoxins [51, 52]. It also increases plasma-endorphin levels and attenuates $N$-methyl-D-aspartate (NMDA)-mediated nociceptive discharge via the L-arginine-nitric oxide-cGMP (cyclic guanosine monophosphate) pathway $[49,51,53]$. Diclofenac has been shown to reduce prostaglandin and interleukin- 6 levels in plasma and synovial fluid in patients with rheumatoid arthritis and osteoarthritis $[51,54,55]$. Compared with other NSAIDs, irrespective of COX-specificity, diclofenac shows greater inhibition of platelet aggregation and acts as a competitive antagonist of thromboxane-prostanoid receptor, signifying potential cardiovascular safety $[51,56]$.

\section{PHARMACOKINETIC PROPERTIES}

The data for the pharmacokinetics of tramadol/ diclofenac FDC are obtained largely from the product characteristics of tramadol and diclofenac combinations [57]. Investigating the pharmacokinetics of this FDC will be of future interest.

\section{Tramadol}

After oral administration, tramadol is quickly and completely absorbed. Its absorption is delayed by approximately $30 \mathrm{~min}$, and 
absorption half-life is $23 \pm 11 \mathrm{~min}$. Plasma concentration and area under the concentration-time curve (AUC) increase linearly over a dose range of $50-400 \mathrm{mg}$ [58]. Mean peak plasma concentration $\left(C_{\max }\right)$ is $280 \mathrm{ng} / \mathrm{mL}$ [57]. The mean absolute bioavailability of tramadol is $68-72 \%$, corresponding to $20-30 \%$ first-pass metabolism [57, 58]. Tramadol is rapidly distributed in the body, with a volume of distribution of $2-3 \mathrm{~L} / \mathrm{kg}$ in young adults, which reduces by about $25 \%$ in elderly patients ( $\geq 75$ years). It effectively crosses the placental and blood-brain barriers, and small amounts $(0.1 \%)$ are excreted in breast milk $[37,57,58]$. Tramadol achieves peak brain concentration 10 min after oral administration; the corresponding value for active metabolite $\mathrm{M} 1$ is 20-60 min [58]. It shows $20 \%$ protein binding [57].

Following oral administration, tramadol is extensively metabolised in the liver, largely via $\mathrm{O}$ - and $\mathrm{N}$-demethylation and conjugation reactions forming glucuronides and sulphates [58]. CYP2D6 catalyses $O$-demethylation of tramadol to the pharmacologically active metabolite, M1, whereas CYP3A4 and CYP2B6 catalyse $\mathrm{N}$ demethylation of tramadol to the metabolite $\mathrm{N}$ desmethyltramadol (M2) [37, 58]. Owing to genetic polymorphisms in the gene encoding CYP2D6, tramadol metabolism varies in different phenotypes [59]. In a study of 104 healthy adult volunteers, those who were poor metabolisers of sparteine, an in vivo probe for CYP2D6 enzyme activity, exhibited significantly higher mean metabolic ratios of tramadol to M1 than extensive metabolisers (4.4 vs. $0.8, p<0.0001$ ) [60]. After a $2 \mathrm{mg} / \mathrm{kg}$ dose of tramadol, poor metabolisers had inferior analgesia and 3- to 33-fold lower concentrations of (+) M1 than extensive metabolisers, influencing the overall therapeutic response and tolerability [61]. Tramadol and its metabolites are excreted predominantly by the kidneys, with a cumulative renal excretion rate of approximately 95\%; about $15-19 \%$ of tramadol is excreted in the urine as unchanged drug, with a total clearance range of $430-610 \mathrm{~mL} / \mathrm{min}$. In young adults, the half-life of tramadol is $5-7 \mathrm{~h}$ and the half-life of M1 is 6-8 h [57].

\section{Diclofenac}

Diclofenac is well absorbed orally and has a calculated apparent volume of distribution of $0.12-0.17 \mathrm{~L} / \mathrm{kg}$ [57]. The AUC of diclofenac is proportional to the orally administered dose between 25 and $150 \mathrm{mg}$. Peak concentration in synovial fluid, which is the site of action of NSAIDs, is achieved 2-4 h after attaining peak plasma levels [57]. Diclofenac binds extensively to plasma proteins $(99.7 \%)$, mainly albumin $[57,62]$.

Following oral administration, biotransformation of diclofenac is ensured mainly by single and multiple hydroxylation, methoxylation, and partial glucuronidation, resulting in phenolic metabolites which are then converted to glucuronide conjugates. Total systemic clearance of diclofenac is $263.56 \mathrm{~mL} / \mathrm{min}$ [57]. After glucuronidation and sulfation, the metabolites of diclofenac are excreted in the urine (65\%) and bile (35\%) [30]. Elimination from synovial fluid takes around 3-6 h [57]. The terminal halflife in plasma is $1-2 \mathrm{~h}[30,43,57]$.

\section{Drug Interactions and Pharmacokinetics in Special Populations}

The tramadol/diclofenac FDC is not recommended for patients with severe renal impairment [57, 63]. Approximately $25 \%$ of medications, such as antiarrhythmic, antiemetics, antidepressants, antipsychotics, analgesics, and tamoxifen, are metabolised by the CYP2D6 enzymes, many of which are commonly administered to ambulatory patients receiving tramadol and are likely to cause drug-drug interactions [64]. Concurrent use of tramadol and serotonergic medications results in a hyperserotonergic state soon after treatment initiation or changes in the doses of serotonergic medications. The underlying reason for this effect is the inhibition of metabolic enzymes [42]. The combination of tramadol with partial opiate agonists/antagonists and abrupt cessation of tramadol is not advisable due to risk of withdrawal symptoms [42]. Concomitant use of coumarin derivatives and tramadol may lead to an increased international 
normalised ratio which may lead to major bleeding and ecchymosis in some patients $[37,57]$. Co-administration with carbamazepine causes significant increase in tramadol metabolism, presumably through metabolic induction which raises the recommended dose of tramadol [58].

In vitro studies indicate that diclofenac has no significant effect on the serum protein binding of acenocoumarol, prednisolone, salicylic acid, tolbutamide, or warfarin [45]. Concomitant administration of antiplatelet medication and anticoagulants with diclofenac could increase the risk of bleeding $[45,57]$. If used concurrently, diclofenac may raise plasma concentrations of lithium by $26 \%$, with a potential risk of intoxication [43]. In hypertensive and/or elderly patients, simultaneous use of diclofenac with antihypertensives (beta-blockers and angiotensin-converting enzyme inhibitors) and potassium-sparing diuretics should be avoided, as it reduces the antihypertensive effects and increases serum potassium levels [57]. Diclofenac raises digoxin and methotrexate concentrations, resulting in increased toxicity of these drugs. It also exhibits nephrotoxic and neurological effects when co-administered with cyclosporine and quinolones, respectively [57]. Like other NSAIDS, diclofenac should be used at the lowest effective dose for the shortest duration to reduce the risk of severe hepatic reactions [50].

\section{DOSAGE AND ADMINISTRATION}

The recommended dose of tramadol/diclofenac FDC is one tablet twice daily after meals, for a period not exceeding 5 days [57]. This combination is indicated for symptomatic treatment of severe pain in adults with severe acute pain of trauma, postoperative pain, low back pain, and musculoskeletal pain. Tramadol is recommended as an important WHO step 2 analgesic and is widely prescribed in clinical practice for the treatment of acute pain, labour pain, and chronic cancer and non-cancer pain $[65,66]$. Tramadol is prescribed when paracetamol and/ or NSAIDs and COX-2 inhibitors alone are inadequate and strong opioids are not warranted or available. The use of tramadol in pain management has increased because of the serious safety issues associated with NSAIDs (GI bleeding) and COX-2 inhibitors (cardiovascular risks, nephrotoxicity), which limit their use in elderly patients and special populations [66]. Tramadol should be avoided in pregnant women and nursing mothers [37, 57]. The safety and effectiveness of tramadol/diclofenac FDC is not well studied in paediatric and elderly populations. Caution is warranted when using tramadol in patients with head injury, increased intracranial pressure, and severe impairment of hepatic or renal function, and in patients prone to respiratory depression, addiction, or convulsive disorders [57]. Diclofenac monotherapy is recommended at the lowest effective dose for the shortest duration of action, and is not recommended in patients with cardiovascular events, myocardial infarction, or stroke [57]. NSAIDs reportedly cause an increased risk of serious GI adverse events of bleeding, ulceration, and perforation of the stomach or intestine. Geriatric patients and those with a history of peptic ulcer disease and/or GI bleeding are at greater risk [57]. Local prescribing information should be consulted for information on dosage and administration, contraindications, drug interactions, precautions, and warnings.

\section{THERAPEUTIC EFFICACY}

The tramadol/diclofenac combination demonstrated synergistic interactions in experimental nociceptive models, which provide the rationale for its use in acute severe pain [67]. This combination has complementary modes of action and targets multiple sites, as shown in Fig. 1. Limited evidence is available to support the efficacy of tramadol/diclofenac combinations. This section summarises data from a phase III trial of the tramadol/diclofenac FDC (CTRI/2011/091/000150 registered on: 01/02/ 2011) and a post-marketing observational study. Studies using different dosages and routes of administration for tramadol and diclofenac are also included to illustrate the additive effects of the combination. 


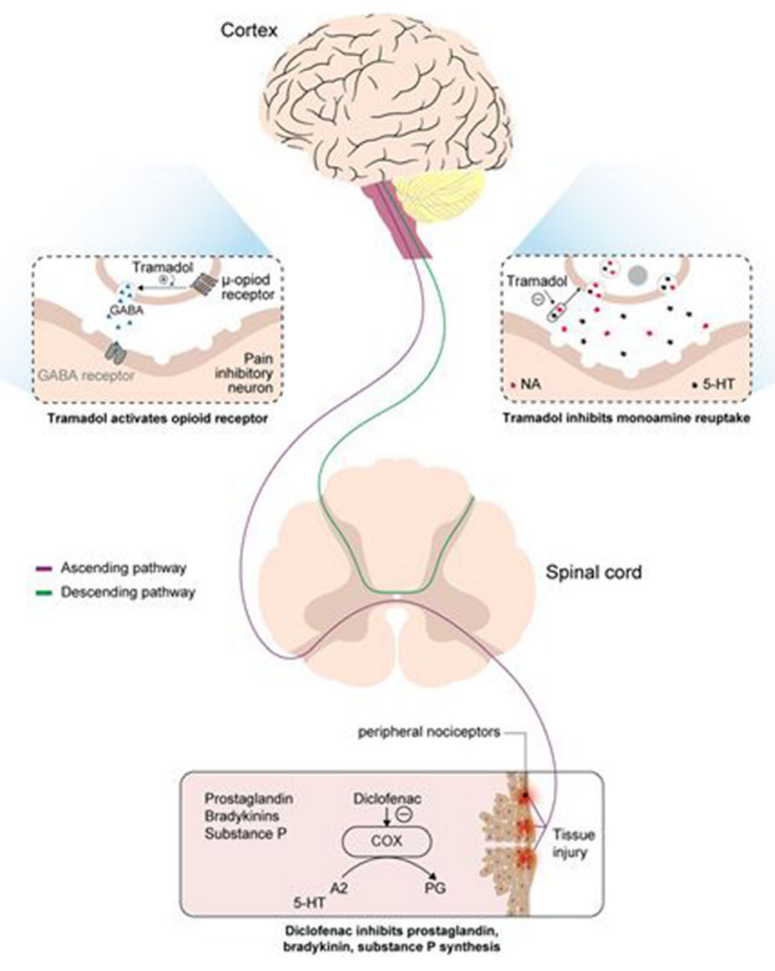

GABA: $\gamma$-aminobutyric acid; COX: Cyclooxygenase; 5-HT: 5-hydrocytryptamine; MOR: $\mu$-opioid receptor;

NA: Noradrenaline; PG: Prostaglandin; A2: Thromboxane-A2

Fig. 1 Complementary modes of action of a tramadol/diclofenac combination [36, 38, 49-51]

The phase III trial included treatment-naïve male and female patients aged $>18$ to $<60$ years with acute pain, characterised by Visual Analog Scale (VAS) score $>50 \mathrm{~mm}$ [68]. Eligible patients were diagnosed with either acute musculoskeletal pain (AMSP; tendinitis, bursitis, synovitis), postoperative pain (POP), or acute flare-up of osteoarthritis (AFOA) or rheumatoid arthritis (AFRA). This 5-day randomised, open-label, comparative, parallelgroup multicentre trial conducted at three centres in India included 204 patients: AMSP $(n=51)$, AFOA $(n=52)$, AFRA $(n=50)$, and POP $(n=50)$. The analgesic efficacy of short-term therapy with tramadol/diclofenac FDC was compared with tramadol/paracetamol FDC [68]. The key efficacy measures defined here are given in Table 1.

The efficacy results are summarised in Fig. 2a. Both FDC treatments significantly reduced overall pain scores on day 3 and day 5; however, the reduction in the VAS scores was greater in patients treated with tramadol/diclofenac FDC than tramadol/paracetamol FDC at day $3(-42.19 \%$ vs. $-29.65 \%, p=0.001)$ and day $5(-67.83 \%$ vs. $-42.87 \%, p=0.0001)$. Similarly, pain relief was significantly better with tramadol/diclofenac when compared with tramadol/paracetamol for pain at rest and pain on movement. Approximately $80 \%$ of patients rated the efficacy of the tramadol/diclofenac FDC as very good or excellent, compared with $19 \%$ of patients treated with tramadol/paracetamol FDC $(p=0.0001)$ [68].

Subgroup analysis showed that the tramadol/ diclofenac FDC achieved significantly greater reduction in pain scores with 3 days of treatment in AFRA and POP patients, while it required 5 days of treatment in AMSP and AFOA patients (Fig. 2b). The analysis of disease- 
Table 1 Key efficacy measures with definitions used in clinical studies

\begin{tabular}{|c|c|}
\hline Outcome measures & Definition \\
\hline WOMAC [69] & $\begin{array}{l}\text { Assessment of pain, stiffness, and physical function and the overall score on a 5-point scale } \\
\text { in patients with acute flare-up of osteoarthritis }\end{array}$ \\
\hline HAQ scale [70] & $\begin{array}{l}\text { Assessment contains } 8 \text { items rated on a 4-point scale in patients with acute flare-up of } \\
\text { rheumatoid arthritis }\end{array}$ \\
\hline NRS [71] & $\begin{array}{l}\text { On a } 6 \text {-point rating scale }(0=\text { no pain and } 5=\text { the worst pain, the higher the score, the } \\
\text { worse the pain) in patients with postoperative pain }\end{array}$ \\
\hline Pain intensity, pain [71] & $\begin{array}{l}\text { Pain intensity and pain was measured with a } 0-100 \mathrm{~mm} \text { VAS scale (for overall pain, pain at } \\
\text { rest, and pain on movement) }\end{array}$ \\
\hline $\begin{array}{c}\text { Global assessment of } \\
\text { effectiveness [72] }\end{array}$ & Assessed on a scale of $1-5$ (1, poor; 2 , satisfactory; 3 , good; 4 , very good; 5 , excellent) \\
\hline
\end{tabular}

WOMAC Western Ontario and McMaster Universities Osteoarthritis Index, HAQ Health Assessment Questionnaire, NRS Numerical Rating Scale

specific pain scores revealed a similar pattern of pain relief (Fig. 2c). Overall, the findings from this phase III trial demonstrated that tramadol/ diclofenac FDC relieves acute pain in AMSP, AFOA, AFRA, and POP patients more effectively than tramadol/paracetamol FDC [68, 72].

The PRIME study-a prospective, multicentre, observational, non-randomised, non-controlled, single-arm post-marketing studyevaluated the real-world efficacy of tramadol/ diclofenac FDC [73]. The study enrolled 351 patients (mean age 44.2 years, from 19 centres in India) who experienced musculoskeletal pain (41.9\%), joint pain (43.9\%), pain due to trauma $(12 \%)$, postoperative pain $(2.85 \%)$, and other types of pain (1.14\%) [73]. The mean pain score was $9.2 \pm 1.09$ at baseline, which was reduced to $5.6 \pm 1.27$ at day 2 (mean reduction $-3.7 \pm 1.41)$ and $2.8 \pm 1.73$ at day 5 $(-6.4 \pm 2.18$ from baseline). The percentage of patients with severe pain was reduced from $100 \%$ at baseline to $18.3 \%$ at day 2 and $6.96 \%$ at day 5 . More than $60 \%$ of patients rated the effectiveness of treatment as "very good to good" [73]. These results substantiated the findings of the phase III trial. In both studies, on tramadol/diclofenac FDC tablet was administered twice daily, whereas tramadol/paracetamol FDC was prescribed at a dosage of two tablets every $4-6 \mathrm{~h}$, up to a maximum of eight tablets daily $[68,72]$. Tramadol/diclofenac FDC offered effective treatment at low doses of individual drugs and reduced the overall pill burden. Severity of pain is an important factor in the selection of analgesic agents by healthcare professionals. Joint pain, traumatic pain, and musculoskeletal conditions are highly prevalent and the most common cause of severe acute pain and physical disability. These two studies support the use of a tramadol/diclofenac FDC, which targets multiple pain pathways and pain transmitter substances, in the management of patients with acute severe inflammatory and traumatic pain $[68,72]$.

In addition to the tramadol/diclofenac FDC studies mentioned above, several other studies have shown adequate pain control with the tramadol/diclofenac combination compared with either of the individual drugs or with paracetamol $[35,74]$. In a randomised trial, pain intensity ratings at rest were significantly lower with the tramadol/diclofenac combination than with tramadol/placebo (at $30 \mathrm{~min}, 6 \mathrm{~h}$, and $7 \mathrm{~h}$ post-injection, $p<0.04$ ) and double placebo (at 30 and $60 \mathrm{~min}$ and 6 and $7 \mathrm{~h}, p<0.05$ ) when administered intramuscularly in women undergoing Caesarean section [34]. Pain ratings during movement were lower with the tramadol/diclofenac combination than with double placebo at $60 \mathrm{~min}$ and $6 \mathrm{~h}$ post-injection $(p<0.04$ and $p<0.0008$, respectively) [34]. Post-Caesarean section intramuscular 

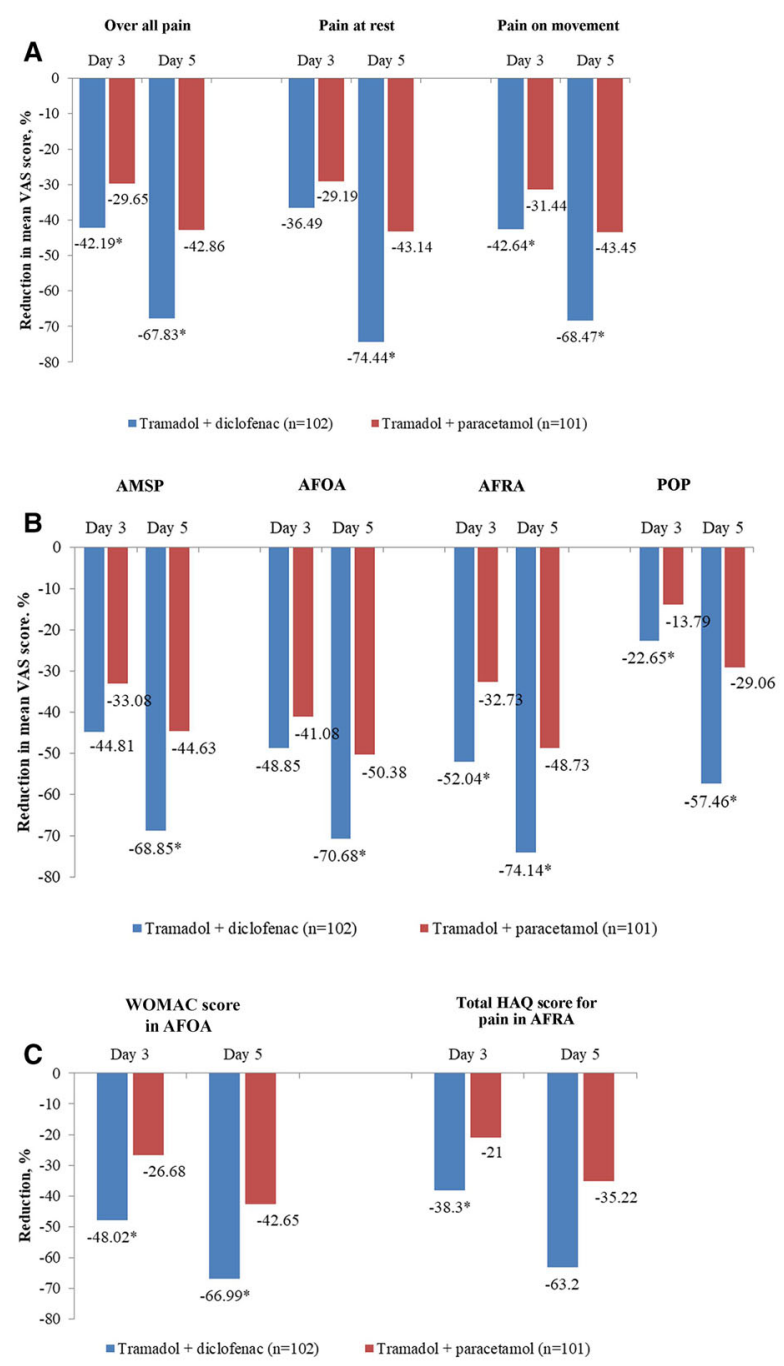

Fig. 2 a Reduction in mean VAS score (pooled data) [68]. b Reduction in mean VAS score in subgroup [68]. c Reduction in WOMAC score in AFOA and total HAQ score for pain in AFRA [68]. *All $p<0.05$ for tramadol + diclofenac vs. tramadol + paracetamol. $V A S$ Visual Analog Scale, WOMAC Western Ontario and McMaster Universities Osteoarthritis Index, $A F O A$ Acute Flare-up of Osteoarthritis, $H A Q$ Health Assessment Questionnaire, AFRA Acute Flare-up of Rheumatoid Arthritis, AMSP Acute Musculoskeletal Pain, POP Postoperative Pain

administration of tramadol/diclofenac combination reduced both primary and secondary hyperalgesia compared with their monotherapy, which reduced only primary hyperalgesia. This has significant clinical relevance, as surgery causes hyperalgesia and allodynia at both local and distal sites [34].

In another randomised, double-blind, parallel-group study, Mitra et al. compared diclofenac/tramadol with diclofenac/paracetamol for pain relief after Caesarean section, which showed that overall pain scores for the entire observational period, measured as AUC, were significantly lower in the diclofenac/tramadol group [74]. In another randomised trial, tramadol/diclofenac had shorter onset and longer duration of analgesia and reduced $\mathrm{AE}$ incidence compared with the individual drugs [35].

\section{TOLERABILITY}

This section focuses on tolerability data from the clinical trials discussed above. Chandanwale et al. assessed the safety of tramadol/diclofenac FDC versus tramadol/paracetamol FDC in patients with acute severe pain with respect to changes in swelling score, inflammation score, and number of rescue medications needed (Table 2) [68]. The tramadol/diclofenac FDC was associated with fewer AEs. The proportion of patients who experienced AEs on day 5 was significantly lower in the tramadol/diclofenac FDC group compared with the tramadol/paracetamol FDC group ([8.82\%] vs. $21.78 \%$, $p=0.019)$. Most frequently observed AEs were nausea and vomiting, and their incidence was numerically greater in patients receiving tramadol/paracetamol FDC (Table 2). The swelling and inflammation scores and the need for rescue medication were low on both day 3 and day 5 in patients receiving tramadol/diclofenac FDC (Table 2). Global tolerability assessment was good in $77 \%$ of patients treated with tramadol/ diclofenac FDC, compared with $42 \%$ for tramadol/paracetamol FDC $(p<0.0001)$. Differences in the incidence of AEs were attributable to different doses of FDCs. Nausea and vomiting are important dose-dependent GI AEs which are associated with tramadol and can be prevented prophylactically by treatment with antiemetic and gastro-protective agents. Shah et al. observed similar results: global tolerability was rated as very good to good in $68.36 \%$ of patients treated with tramadol/ 
Table 2 Safety and tolerability parameters for tramadol/diclofenac FDC and tramadol/paracetamol FDC (pooled data) [68]

\begin{tabular}{lccc}
\hline Safety parameter & $\begin{array}{l}\text { Tramadol + diclofenac } \\
(\boldsymbol{n}=\mathbf{1 0 2})\end{array}$ & $\begin{array}{l}\text { Tramadol + paracetamol } \\
(\boldsymbol{n}=\mathbf{1 0 1})\end{array}$ & $\boldsymbol{p}$ value \\
\hline Mean swelling score & $\mathrm{a}$ & $1.84(0.90)$ & 0.805 \\
Baseline mean (SEM) & $1.88(0.91)$ & $-0.41(-22.32)$ & 0.0001 \\
Day 3 & $-0.94(-50.00)$ & $-0.93(-50.57)$ & 0.0001 \\
Day 5 & $-1.44(-76.69)$ & & 0.373 \\
Total inflammation score & & $3.22(1.58)$ & 0.0001 \\
Baseline mean (SEM) & $3.44(1.64)$ & $-0.90(-28.05)$ & 0.0001 \\
Day3 & $-1.83(-53.05)$ & $-1.75(-54.21)$ & \\
Day 5 & $-2.82(-81.99)$ & &
\end{tabular}

Rescue medication ${ }^{\mathrm{b}}$

$\begin{array}{lllr}\text { Baseline } & 1(4) & 2(10) & \\ \text { Day } 3 & 2(3) & 2(7) & <0.0001 \\ \text { Day } 5 & 1(2) & 2(5) & 0.0193 \\ \text { Total no. of tablets, (\%) } & 8(7.92) & 44(43.56) & 22(21.78)\end{array}$

Adverse events, $n$ (\%)

Day 3

Drowsiness

$0(0)$

$1(0.98)$

Epigastric pain

$1(0.98)$

1 (0.98)

Gastritis

3 (2.94)

5 (4.90)

Nausea

$6(5.88)$

23 (22.55)

Vomiting

$6(5.88)$

16 (15.69)

Total events

16 (15.68)

46 (45.10)

$<0.0001$

Day 5

Drowsiness

Epigastric pain

$0(0)$

0 (0)

Gastritis

1 (0.98)

2 (1.96)

Nausea

2 (1.96)

0 (0)

Vomiting

4 (3.92)

14 (13.73)

Total events

2 (1.96)

6 (5.88)

9 (8.82)

22 (21.57)

0.019

$F D C$ fixed-dose combination, SEM standard error of the mean

${ }^{a}$ All data points are mean change (\% change) unless otherwise indicated

b All data points are number of tablets (number of patients unless mentioned) 
diclofenac FDC [73]. In this study, five (1.42\%) patients developed nine GI-related AEs; however, these AEs resolved after drug discontinuation [73]. In a study by Mitra et al. the incidence of side effects and the use of rescue analgesics were similar $(p=0.872)$ in patients treated with intravenous tramadol/diclofenac combination compared with tramadol/paracetamol combination [74]. A low incidence of vomiting, drowsiness, and dizziness was reported in patients undergoing elective Caesarean section under spinal anaesthesia who were treated with diclofenac/tramadol FDC compared with monotherapy with either drug [35]. The incidence of nausea and vomiting in this study was comparable to those reported by Smith et al. [34].

\section{CURRENT PLACE OF TRAMADOL/ DICLOFENAC IN MANAGEMENT OF SEVERE ACUTE PAIN}

According to the WHO ladder, the combination of paracetamol or NSAIDs (diclofenac) with weak opioids (tramadol, codeine) is considered as the second step in the treatment of pain, based on an increase in the severity of pain $[23,68]$. Similarly, an expert panel consensus for pharmacological treatment of acute pain in the Middle East recommends NSAIDs or selective COX inhibitors: diclofenac as step 2 treatment for severe pain and as step 1 for patients for whom paracetamol provides inadequate analgesia. Tramadol is also recommended as a widely prescribed step 2 analgesic in clinical practice for acute pain [75]. Given the multimodal origin of pain pathways, the concept of a platform, rather than a ladder, for appropriate selection of analgesic agents has recently gained popularity [23]. A clinician may choose an appropriate platform to explore treatment options based on a patient's clinical characteristics [23]. Recent pain management guidelines have recognised the importance of multimodal analgesia for the treatment of acute pain $[23,76-79]$. The objective of multimodal analgesia is to enhance analgesia and reduce potential AEs by combining analgesics from different drug classes with different modes of action $[23,80]$. This can be attained by freely combining analgesics or with FDCs, the latter being simpler and more convenient to use $[23,80]$. Tramadol/diclofenac FDC provides multimodal analgesic pain relief due to complementary and synergistic mechanisms of action, with a lower risk of AEs and dependency. Clinical studies evaluating tramadol/diclofenac FDC have so far demonstrated a safe, effective, and well-tolerated profile. We believe that this multimodal analgesic FDC may be used in routine clinical practice based on individualised patient needs.

\section{LIMITATIONS}

Currently, data supporting the efficacy and safety of tramadol/diclofenac combinations are scarce. This review provides interesting insights into the efficacy and safety of tramadol/diclofenac FDC for management of acute severe pain in randomised and real-life settings. However, the effects of this combination are yet to be evaluated in special populations such as older patients or those with cancer, and hence should be the subject of future research.

\section{CONCLUSIONS}

Current clinical evidence supports the efficacy of tramadol/diclofenac FDC versus tramadol/paracetamol FDC for the treatment of acute severe pain. Further, the low-dose regimen of tramadol/diclofenac FDC reduces the incidence of AEs and improves patient compliance. Therefore, tramadol/diclofenac FDC could be an effective alternative to tramadol/paracetamol FDC for the treatment of acute pain. However, studies evaluating the benefits in special populations are needed. In our opinion, tramadol/diclofenac FDC appears to be an effective and well-tolerated multimodal analgesic FDC for short-term treatment of acute severe pain and could be recommended in routine clinical practice. 


\section{ACKNOWLEDGEMENTS}

Funding. The journal's Rapid Service Fee was funded by Abbott Healthcare Pvt. Ltd. No funding or sponsorship was received for this study.

Medical Writing, Editorial, and Other Assistance. Writing assistance was provided by Leena Patel and Sonali Dalwadi from CBCC Global Research, through academic funding from Abbott Healthcare Pvt. Ltd.

Authorship. All authors meet the International Committee of Medical Journal Editors (ICMJE) criteria for authorship of this manuscript, take complete responsibility for the accuracy and integrity of the work as a whole, and have given their approval for this version to be published.

Disclosures. Dilip D. Shah and Zubair H. Sorathia have nothing to disclose.

Compliance with Ethics Guidelines. This article is based on previously conducted studies and does not contain any studies with human participants or animals performed by any of the authors.

Data Availability. Data sharing is not applicable to this article, as no data sets were generated or analyzed during the current study.

Open Access. This article is licensed under a Creative Commons Attribution-NonCommercial 4.0 International License, which permits any non-commercial use, sharing, adaptation, distribution and reproduction in any medium or format, as long as you give appropriate credit to the original author(s) and the source, provide a link to the Creative Commons licence, and indicate if changes were made. The images or other third party material in this article are included in the article's Creative Commons licence, unless indicated otherwise in a credit line to the material. If material is not included in the article's Creative Commons licence and your intended use is not permitted by statutory regulation or exceeds the permitted use, you will need to obtain permission directly from the copyright holder. To view a copy of this licence, visit http://creativecommons.org/licenses/by$\mathrm{nc} / 4.0 /$.

\section{REFERENCES}

1. The International Association of Pain (IASP) Terminology. 2018. http://www.iasp-pain.org/ Education/Content.aspx?ItemNumber $=1698$. Assessed 27 Nov 2018.

2. Goldberg DS, McGee SJ. Pain as a global public health priority. BMC Public Health. 2011;11:770-5.

3. Carr DB, Goudas LC. Acute pain. Lancet. 1999;353(9169):2051-8.

4. Couceiro TC, Valença MM, Lima LC, de Menezes TC, Raposo MC. Prevalence and influence of gender, age, and type of surgery on postoperative pain. Rev Bras Anesthesiol. 2009;59(3):314-20.

5. Mwaka G, Thikra S, Mun'gayi V. The prevalence of postoperative pain in the first 48 hours following day surgery at a tertiary hospital in Nairobi. Afr Health Sci. 2013;13(3):768-76.

6. Machado-Alba JE, Machado-Duque ME, Flórez VC, Montoya AG, Escobar FC, García RR, Cataño JM. Are we controlling postoperative pain? Rev Colomb Anesthesiol. 2013;41(2):132-8.

7. Sommer M, De Rijke JM, Van Kleef M, Kessels AG, Peters ML, Geurts JW, Gramke HF, Marcus MA. The prevalence of postoperative pain in a sample of 1490 surgical inpatients. Eur J Anaesthesiol. 2008;25(4):267-74.

8. Singh PK, Saikia P, Lahakar M. Prevalence of acute post-operative pain in patients in adult age-group undergoing inpatient abdominal surgery and correlation of intensity of pain and satisfaction with analgesic management: a cross-sectional single institute-based study. Indian $\mathrm{J}$ Anaesth. 2016;60(10):737-43.

9. Yasobant S, Mohanty S. Musculoskeletal disorders as a public health concern in India: a call for action. Physiother J Indian Assoc Physiother. 2018;12(1): 46-7.

10. Sinatra R. Causes and consequences of inadequate management of acute pain. Pain Med. 2010;11(12): 1859-71. 
11. Gan TJ. Poorly controlled postoperative pain: prevalence, consequences, and prevention. J Pain Res. 2017;10:2287-98.

12. Langley P, Müller-Schwefe G, Nicolaou A, Liedgens $H$, Pergolizzi J, Varrassi G. The impact of pain on labor force participation, absenteeism and presenteeism in the European Union. J Med Econ. 2010;13(4):662-72.

13. Langley P, Müller-Schwefe G, Nicolaou A, Liedgens $H$, Pergolizzi J, Varrassi G. The societal impact of pain in the European Union: health-related quality of life and healthcare resource utilization. J Med Econ. 2010;13(3):571-81.

14. Wardhan R, Chelly J. Recent advances in acute pain management: understanding the mechanisms of acute pain, the prescription of opioids, and the role of multimodal pain therapy. F1000Research. 2017;6:2065.

15. Kuusniemi K, Pöyhiä R. Present-day challenges and future solutions in postoperative pain management: results from pain forum 2014. J Pain Res. 2016;9:25-36.

16. Mowat I, Johson D. Acute pain management part 2 assessment and management. Anaesth Tutor Week. 2013;1(1):1-9.

17. Rupp $\mathrm{T}$, Delaney KA. Inadequate analgesia in emergency medicine. Ann Emerg Med. 2004;43(4): 494-503.

18. Yekkirala AS, Roberson DP, Bean BP, Woolf CJ. Breaking barriers to novel analgesic drug development. Nat Rev Drug Discov. 2017;16(8):545-64.

19. Dureja GP, Iyer RN, Das G, Ahdal J, Narang P. Evidence and consensus recommendations for the pharmacological management of pain in India. J Pain Res. 2017;10:709-36.

20. Derry P, Derry S, Moore RA, McQuay HJ. Single dose oral diclofenac for acute postoperative pain in adults. Cochrane Database Syst Rev. 2009;2: CD004768.

21. Schug SA, Garrett WR, Gillespie G. Opioid and nonopioid analgesics. Best Pract Res Clin Anaesthesiol. 2003;17(1):91-110.

22. Moore RA, Derry CJ, Derry S, Straube S, McQuay HJ. A conservative method of testing whether combination analgesics produce additive or synergistic effects using evidence from acute pain and migraine. Eur J Pain. 2012;16(4):585-91.

23. Raffa RB, Tallarida RJ, Taylor R Jr, Pergolizzi JV Jr. Fixed-dose combinations for emerging treatment of pain. Expert Opin Pharmacother. 2012;13(9): 1261-70.

24. Gaskell H, Derry S, Moore RA, McQuay HJ. Single dose oral oxycodone and oxycodone plus paracetamol (acetaminophen) for acute postoperative pain in adults. Cochrane Database Syst Rev. 2009;3: CD002763.

25. Oldfield V, Perry CM. Oxycodone/ibuprofen combination tablet: a review of its use in the management of acute pain. Drugs. 2005;65(16):2337-54.

26. Filitz J, Ihmsen H, Günther W, Tröster A, Schwilden H, Schüttler J, Koppert W. Supra-additive effects of tramadol and acetaminophen in a human pain model. Pain. 2008;136(3):262-70.

27. Santini MF, Rosa RA, Ferreira MB, Fischer MI, Souza EM, Só MV. Comparison of two combinations of opioid and non-opioid analgesics for acute periradicular abscess: a randomized clinical trial. J Appl Oral Sci. 2017;25(5):551-8.

28. Roberts E, Nunes VD, Buckner S, Latchem S, Constanti M, Miller P, Doherty M, Zhang W, Birrell F, Porcheret M, Dziedzic K. Paracetamol: not as safe as we thought? A systematic literature review of observational studies. Ann Rheum Dis. 2016;75(3): 552-9.

29. Scarpignato C, Lanas A, Blandizzi C, Lems WF, Hermann M, Hunt RH, International NSAID Consensus Group. Safe prescribing of non-steroidal anti-inflammatory drugs in patients with osteoarthritis-an expert consensus addressing benefits as well as gastrointestinal and cardiovascular risks. BMC Med. 2015;13:55-76.

30. Grosser T, Smyth E, FitzGerald GA. Chapter 26. Anti-inflammatory, antipyretic, and analgesic agents; pharmacotherapy of gout. In: Brunton, Hilal-Dandan, Knollman, editors. Goodman and Gilman's the pharmacological basis of therapeutics, 11th ed. McGraw-Hill; 2011. pp. 959-1004.

31. da Costa BR, Reichenbach S, Keller N, et al. Effectiveness of non-steroidal anti-inflammatory drugs for the treatment of pain in knee and hip osteoarthritis: a network meta-analysis. Lancet. 2016;387:2093-105.

32. Nauta M, Landsmeer ML, Koren G. Codeine-acetaminophen versus nonsteroidal anti-inflammatory drugs in the treatment of post-abdominal surgery pain: a systematic review of randomized trials. Am J Surg. 2009;198:256-61.

33. Machado GC, Maher CG, Ferreira PH, Pinheiro MB, Lin CW, Day RO, McLachlan AJ, Ferreira ML. Efficacy and safety of paracetamol for spinal pain and osteoarthritis: systematic review and meta-analysis 
of randomised placebo controlled trials. BMJ. 2015;350:h1225.

34. Wilder-Smith CH, Hill L, Dyer RA, Torr G, Coetzee E. Postoperative sensitization and pain after cesarean delivery and the effects of single im doses of tramadol and diclofenac alone and in combination. Anesth Analg. 2003;97(2):526-33.

35. Shareef SM, Sridhar I, Dakshayani KM, Rao YV, Santhamma B. Evaluation of the effects of tramadol and diclofenac alone and in combination on postcesarean pain. Int $\mathrm{J}$ Basic Clin Pharmacol. 2017;3(3):470-3.

36. Raffa R. Pharmacological aspects of successful longterm analgesia. Clin Rheumatol. 2006;25(S1):9-15.

37. Scott LJ, Perry CM. Tramadol: a review of its use in perioperative pain. Drugs. 2000;60(1):139-76.

38. Lee CR, McTavish D, Sorkin EM. Tramadol. Drugs. 1993;46(2):313-40.

39. Gutstein HB, Akil H. Chapter 21. Opioid analgesics. In: Brunton, Hilal-Dandan, Knollman, editors. Goodman and Gilman's the pharmacological basis of therapeutics. 11th ed. McGraw-Hill; 2011. pp. 547-590.

40. Gillen C, Haurand M, Kobelt DJ, Wnendt S. Affinity, potency and efficacy of tramadol and its metabolites at the cloned human $\mu$-opioid receptor. Naunyn-Schmiedeberg's Arch Pharmacol. 2000;362(2):116-21.

41. Beakley BD, Kaye AM, Kaye AD. Tramadol, pharmacology, side effects, and serotonin syndrome: a review. Pain Physician. 2015;18(4):395-400.

42. Miotto K, Cho AK, Khalil MA, Blanco K, Sasaki JD, Rawson R. Trends in tramadol: pharmacology, metabolism, and misuse. Anesth Analg. 2017;124(1):44-51.

43. Todd PA, Sorkin EM. Diclofenac sodium. A reappraisal of its pharmacodynamic and pharmacokinetic properties, and therapeutic efficacy. Drugs. 1988;35(3):244-85.

44. Franceschi F, Saviano L, Petruzziello C, Gabrielli M, Santarelli L, Capaldi L, Di Leo M, Migneco A, Gilardi E, Merra G, Ojetti V. Safety and efficacy of low doses of diclofenac on acute pain in the emergency setting. Eur Rev Med Pharmacol Sci. 2016;20(20):4401-8.

45. Kołodziejska J, Kołodziejczyk M. Diclofenac in the treatment of pain in patients with rheumatic diseases. Reumatologia. 2018;56(3):174-83.
46. Dhillon S. Tramadol/paracetamol fixed-dose combination: a review of its use in the management of moderate to severe pain. Clin Drug Investig. 2010;30(10):711-38.

47. Driessen B, Reimann W, Giertz H. Effects of the central analgesic tramadol on the uptake and release of noradrenaline and dopamine in vitro. $\mathrm{Br} \mathrm{J}$ Pharmacol. 1993;108(3):806-11.

48. Dayer P, Desmeules J, Collart L. Pharmacologie du tramadol. Drugs. 1997;53(2):18-24.

49. Jhunjhunwala HR, Naik AK. New dimension in pain management: diclofenac-colestyramine. Indian J Clin Pract. 2012;22(12):23-7.

50. Ku EC, Lee W, Kothari HV, et al. Effect of diclofenac sodium on the arachidonic acid cascade. Am J Med. 1986;80(4B):18-23.

51. Gan TJ. Diclofenac: an update on its mechanism of action and safety profile. Curr Med Res Opin. 2010;26(7):1715-31.

52. Clish CB, Sun YP, Serhan CN. Identification of dual cyclooxygenase-eicosanoid oxidoreductase inhibitors: NSAIDs that inhibit PG-LX reductase/LTB(4) dehydrogenase. Biochem Biophys Res Commun. 2001;288(4):868-74.

53. Dong XD, Svensson P, Cairns BE. The analgesic action of topical diclofenac may be mediated through peripheral NMDA receptor antagonism. Pain. 2009;147(1-3):36-45.

54. González E, Cruz C, Nicolás R, Egido J, HerreroBeaumont G. Long-term effect of nonsteroidal antiinflammatory drugs on the production of cytokines and other inflammatory mediators by blood cells of patients with osteoarthritis. Agents Actions. 1994;41(3-4):171-8.

55. Sacerdote P, Carrabba M, Galante A, Pisati R, Manfredi B, Panerai AE. Plasma and synovial fluid interleukin-1, interleukin-6 and substance P concentrations in rheumatoid arthritis patients: effect of the nonsteroidal anti-inflammatory drugs indomethacin, diclofenac and naproxen. Inflamm Res. 1995;44(11):486-90.

56. Selg E, Buccellati C, Andersson M, Rovati GE, Ezinga M, Sala A, Larsson AK, Ambrosio E, Låstbom L, Capra V, Dahlén B. Antagonism of thromboxane receptors by diclofenac and lumiracoxib. $\mathrm{Br} \mathrm{J}$ Pharmacol. 2007;152(8):1185-95.

57. Product Information: DURAPAIN ${ }^{\circledR}$, obtained from Abbott Healthcare Pvt. Ltd. 
58. Grond S, Sablotzki A. Clinical pharmacology of tramadol. Clin Pharmacokinet. 2004;43(13): 879-923.

59. Tramadol updated review: WHO. 2018. http:// www.who.int/medicines/access/controlledsubstances/Tramadol.pdf. Assessed 30 Nov 2018.

60. Paar WD, Poche S, Gerloff J, Dengler HJ. Polymorphic CYP2D6 mediates O-demethylation of the opioid analgesic tramadol. Eur J Clin Pharmacol. 1997;53(3-4):235-9.

61. Poulsen L, Arendt-Nielsen L, Brosen K, Sindrup SH. The hypoalgesic effect of tramadol in relation to CYP2D6. Clin Pharmacol Ther. 1996;60(6):636-44.

62. Davies NM, Anderson KE. Clinical pharmacokinetics of diclofenac. Clin Pharmacokinet. 1997;33(3): 184-213.

63. Adikwu E, Nelson EC. Assessments of kidney function and morphology of tramadol-diclofenac treated albino rats. Adv Life Sci. 2018;5(3):104-12.

64. Ingelman-Sundberg M. Genetic polymorphisms of cytochrome P450 2D6 (CYP2D6): clinical consequences, evolutionary aspects and functional diversity. Pharmacogenom J. 2005;5(1):6-13.

65. Comments to WHO (ECDD) tramadol update review report. 2014. http://www.who.int/ medicines/areas/quality_safety/TRAMADOL_ IFPMA_Comments.pdf. Assessed 30 Nov 2018.

66. World Health Organization. WHO's pain ladder. 2018. http://www.who.int/cancer/palliative/ painladder/en/. Assessed 01 Dec 2018.

67. Rodríguez-Silverio J, Déciga-Campos M, Reyes-García G, Carrasco-Portugal MD, Flores-Murrieta FJ. Evaluation of the interaction between tramadol and diclofenac in several models of nociception in the rat. Drug Dev Res. 2011;72(5):391-6.

68. Chandanwale AS, Sundar S, Latchoumibady K, Biswas S, Gabhane M, Naik M, Patel K. Efficacy and safety profile of combination of tramadol-diclofenac versus tramadol-paracetamol in patients with acute musculoskeletal conditions, postoperative pain, and acute flare of osteoarthritis and rheumatoid arthritis: a phase III, 5-day open-label study. J Pain Res. 2014;7:455-63.

69. Western Ontario and McMaster Universities Osteoarthritis Index (WOMAC). American College of Rheumatology Research Committee. 2012. https://www.rheumatology.org/Practice/Clinical/ Clinicianresearchers/Outcomes_Instrumentation/ Western_Ontario_and_McMaster_Universities_ Osteoarthritis_Index_(WOMAC)/. Assessed 30 Nov 2018.
70. IMACS Form 04a: Instructions for the Health Assessment Questionnaire. 2018. https://www. niehs.nih.gov/research/resources/assets/docs/haq_ instructions_508.pdf. Assessed 30 Nov 2018.

71. Hawker GA, Mian S, Kendzerska T, French M. Measures of adult pain: Visual Analog Scale for Pain (VAS Pain), Numeric Rating Scale for Pain (NRS Pain), McGill Pain Questionnaire (MPQ), ShortForm McGill Pain Questionnaire (SF-MPQ), Chronic Pain Grade Scale (CPGS), Short Form-36 Bodily Pain Scale (SF-36 BPS), and Measure of Intermittent and Constant Osteoarthritis Pain (ICOAP). Arthritis Care Res. 2011;63(S11):S240-52.

72. Billa G, Chandanwale AS, Sundar S, Latchoumibady $\mathrm{K}$, Biswas S. Comparative efficacy and safety evaluation of tramadol plus diclofenac versus tramadol plus paracetamol in a subgroup of Indian patients with moderate to severe acute musculoskeletal pain: a phase III, 5 day open label study. J Exerc Sports Orthop. 2017;4(1):1-6.

73. Shah K, Chaudhari OB, Gupta P, Chaudhuri RH, Kamilya R, Kulkarni SS, Subbaiah S, Sorathia ZH, Billa G. Durapain in symptomatic treatment of severe acute pain: a post-marketing, prospective, multicenter, observational study-PRIME study. J Pain Res. 2017;10:1273-8.

74. Mitra S, Khandelwal P, Sehgal A. Diclofenac-tramadol vs. diclofenac-acetaminophen combinations for pain relief after caesarean section. Acta Anaesthesiol Scand. 2012;56(6):706-11.

75. Ayad AE, Ghaly N, Ragab R, Majeed S, Nassar H, Al Jalabi A, Al Shoaibi A, Noor SE, Salti A, Costandi J, Zeidan AZ. Expert panel consensus recommendations for the pharmacological treatment of acute pain in the Middle East region. J Int Med Res. 2011;39(4):1123-41.

76. European Society of Regional Anaesthesia and Pain Therapy. Postoperative pain management-good clinical practice: general recommendations and principles for successful pain management. 2018. https://www.fpmx.com.au/resources/clinicians/ postoperative-pain-management-good-clinicalpractice.pdf. Assessed 01 Dec 2018.

77. Schug SA, Zech D, Dorr U. Cancer pain management according to WHO analgesic guidelines. J Pain Symptom Manag. 1990;5(1):27-32.

78. Chou R, Gordon DB, de Leon-Casasola OA, Rosenberg JM, Bickler S, Brennan T, Carter T, Cassidy CL, Chittenden EH, Degenhardt E, Griffith S. Management of postoperative pain: a clinical practice guideline from the American Pain Society, the American Society of Regional Anesthesia and Pain Medicine, and the American Society of Anesthesiologists' committee on regional anesthesia, 
executive committee, and administrative council. J Pain. 2016;17(2):131-57.

79. Altman RD, Hochberg MC, Moskowitz RW, Schnitzer TJ. Recommendations for the medical management of osteoarthritis of the hip and knee: 2000 update. American College of Rheumatology
Subcommittee on Osteoarthritis Guidelines. Arthritis Rheum. 2000;43(9):1905-15.

80. Raffa RB, Clark-Vetri R, Tallarida RJ, Wertheimer AI. Combination strategies for pain management. Expert Opin Pharmacother. 2003;4(10):1697-708. 